\title{
A case report: the first successful cochlear implant in Uganda.
}

\author{
Richard Byaruhanga ${ }^{1}$, J. Thomas Roland Jr. ${ }^{2}$, Gustav Buname ${ }^{1}$, Emily Kakande ${ }^{1}$, \\ Michael Awubwa ${ }^{1}$, Chris Ndorelire ${ }^{1}$, Justine Namwagala ${ }^{1}$
}

1. Department of Otolaryngology, School of Medicine, College of Health Sciences, Makerere University, Kampala, Uganda.

2. Department of Otolaryngology, Professor and Chair, New York University School of Medicine

\begin{abstract}
Hearing impairment is a significant disability. According to the World Health Organization (WHO), more than $80 \%$ of the world's approximately 120 million people with hearing impairment live in developing countries. Cochlear implant is the only therapeutic intervention for those with severe-profound sensorineural hearing loss. We are reporting an interesting case of the very first cochlear implant operation carried out in Uganda. The patient was a 23 year old male whose presenting complaint was inability to hear in the left ear for three and a half years and in the right ear for one year. He had been treated for $\mathrm{TB}$ (Tuberculosis) mastoiditis . After the 8 months of treatment, the otorrhea persisted and he underwent a tympanomastoidectomy on the same ear. He reported no familial history of hearing loss. On examination, ENT examination revealed a small pars flaccida retration pocket of the right tympanic membrane with cholesteatoma. The left ear had an intact tympanic membrane. Pure tone audiometry revealed profound sensorineural hearing loss in both ears( see attached PTA results), CT scan of the temporal bone showed normal inner ear anatomy bilaterally and mild sclerotic changes in both mastoid bones. He then had surgery on his right ear which included cochlear implantation. The cochlear implant (CI) was activated on the first postoperative day remotely via internet with the help of the cochlear implant team at New York University Cochlear Implant Center and the patient was immediately able to appreciate some sounds. He received a pneumococcal vaccine on the first postoperative day and was discharged the following day.

Keywords: Cochlear implant, deafness

DOI: http://dx.doi.org/10.4314/ahs.v15i4.38

Cite as: Byarubanga R, Thomas RJrJ, Buname G, Kakande E, Awubwa M, Ndorelire C, et al. A case report: the first successful cocblear implant in Uganda. Afri Health Sci. 2015;15(4):1342-8. bttp:/ / dx.doi.org/10.4314/abs.v15i4.38
\end{abstract}

\section{Introduction}

Hearing impairment is a significant disability. According to the World Health Organization (WHO), more than $80 \%$ of the world's approximately 120 million people with hearing impairment live in developing countries. The causes for hearing loss are varied including presbycusis which causes high frequency loss with advanced age, chronic infectious diseases such as otitis media, meningitis, tuberculosis, congenital factors, ototoxic medications and loud noise exposure. ${ }^{1}$

\section{Corresponding author: \\ Richard Byaruhanga, Makerere University College of Health Sciences, School of Medicine, ENT Department 5th Floor New Mulago Hospital Complex Kampala, Uganda Phone: +256-712 855837 \\ Email: rickybyaru@gmail.com}

Cochlear implant is the only therapeutic intervention for those with severe-profound sensorineural hearing loss. This intervention aids the patient's speech and communication skills and therefore improves on his or her general state of well-being, ability to work and contribute to society. Unfortunately, at present, cochlear implants are unavailable for deaf people in developing countries such as Uganda due to financial and infrastructural constraints. ${ }^{1}$

Such devices are expensive and surgical implantation is only the first part of a process towards restoring hearing which involves speech therapy and frequent visits to the audiologist for device programming.

Feasibility for whether a cochlear implant will actually work in a patient is done in a stepwise manner to answer two questions. These questions are; Are there:

a) Any cochleovestibular anomalies such as evidence of luminal obstruction following infection or secondary to trauma leading to neo-ossification. 
b) Any findings that might complicate surgery such as anatomic variants.

These questions are answered by preoperative imaging either by CT scan or MRI and a complete audiometric evaluation. Other contraindications may include absence of a cochlear nerve which the implant is designed to stimulate and medical cormorbidities which preclude undergoing surgery which can require between 1-3 hours. Factors that predict the greatest success include post-lingual deafness so that patients have already acquired speech and language skills and a short duration of deafness since the longer the ear has been without auditory stimulation, the lower the expectations for speech performance after cochlear implantation.

For successful cochlear implantation the goal is to bypass the inner ear by converting acoustic mechanical energy into electrical impulses transmitted to the existing surviving ganglion cell population in the cochlear which are then relayed via the cochlear nerve to the auditory brainstem and ultimately to the cerebral cortex ${ }^{2}$. In summary, success of the cochlear implant not only depends on the device itself, but also on patient selection, surgical skills, and post-surgical rehabilitation ${ }^{1}$.

\section{History}

The patient was a 23 year old male whose presenting complaint was inability to hear in the left ear for three and a half years and in the right ear for one year. The patient reported that he developed pus discharge from the left ear about 4 years prior to being considered a candidate for a cochlear implant. This ear infection did not respond to standard treatment and was later diagnosed on bacterial and ZN (Ziehl-Neelsen) stains as Tuberculosis of the ear. He was treated with antituberculous medications for 8 months. After the 8 months of treatment, the otorrhea persisted and he underwent a tympanomastoidectomy on the same ear. During recovery, the patient reports that he could not hear from this ear completely.

About 1 year prior to the cochlear implant operation, he developed pain and ear discharge in the right ear for which he was treated with some unspecified ear drops. The pain subsided but later he said he developed reduced hearing that slowly progressed to profound hearing loss in that ear. There was no history of trauma to his head or ears.

He reported no familial history of hearing loss. At the time he became deaf, he was in high school.

On examination, the patient was in good general condition. ENT examination revealed a small pars flaccida retration pocket of the right tympanic membrane with cholesteatoma. The left ear had an intact tympanic membrane . Pure tone audiometry revealed profound sensorineural hearing loss in both ears( see attached PTA results), CT scan of the temporal bone showed normal inner ear anatomy (both cochlear and vestibular apparatus) bilaterally and mild sclerotic changes in both mastoid bones. 


\section{KAMPALAAUDIOLOGY \& SPEECH CENTRE}

Plot 52 Bombo Road, ESAMt House, PO. Hox 35474 Kampala Upanda Tel: 0414-691 743

Names:

$\triangle N$

Fmas: kascentreatyahoouco.uk

$102 / 2008$

Address:

Tel:

Referal/ Advertisement:

P.T. AUDIOGRAM
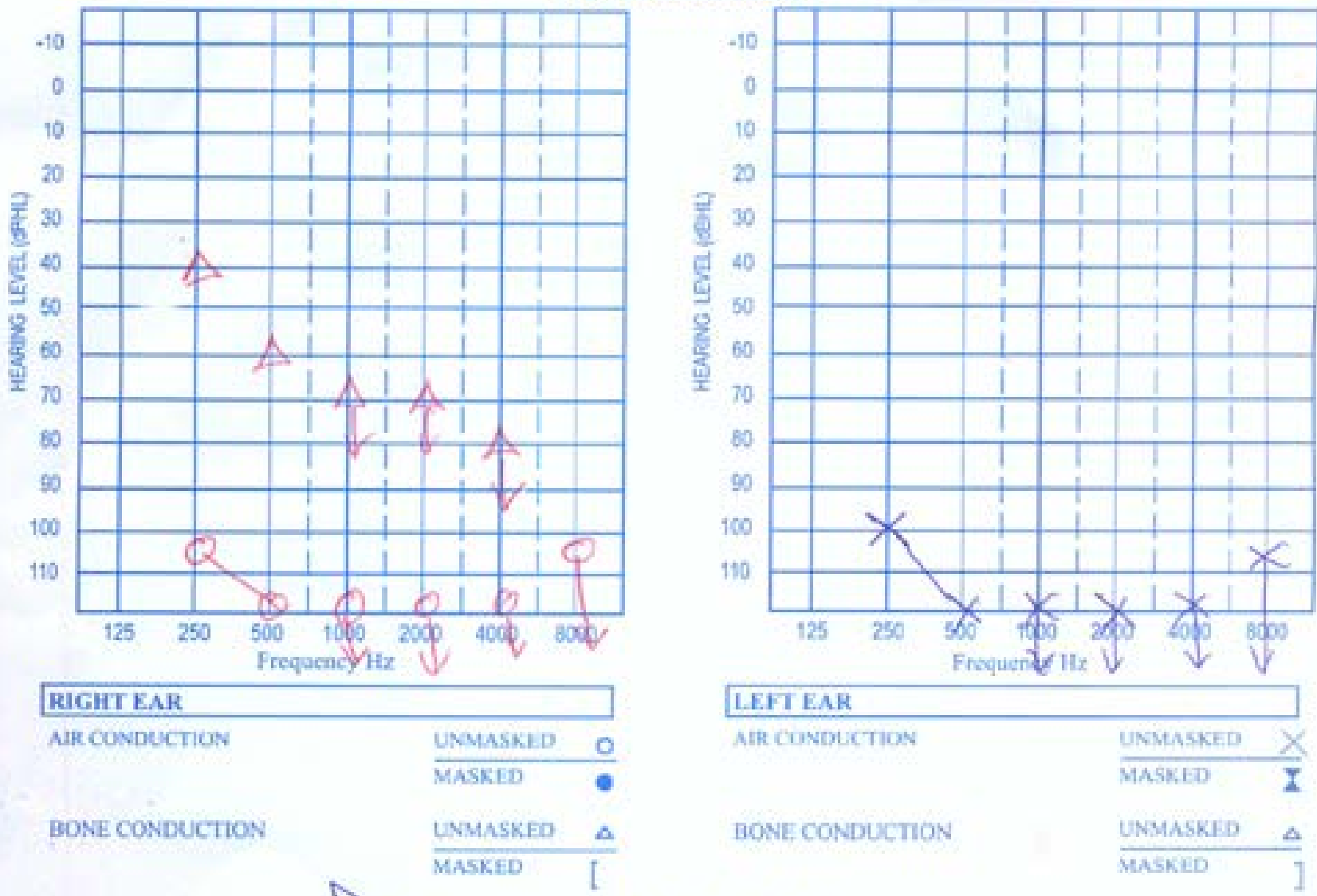

BONE CONDUCTION

$\frac{\text { UNMASKED } \triangle}{\text { MASKED }[}$

Ausiometer type and number. Slagnoshic AD 206

SPEECH AUDIOGRAM

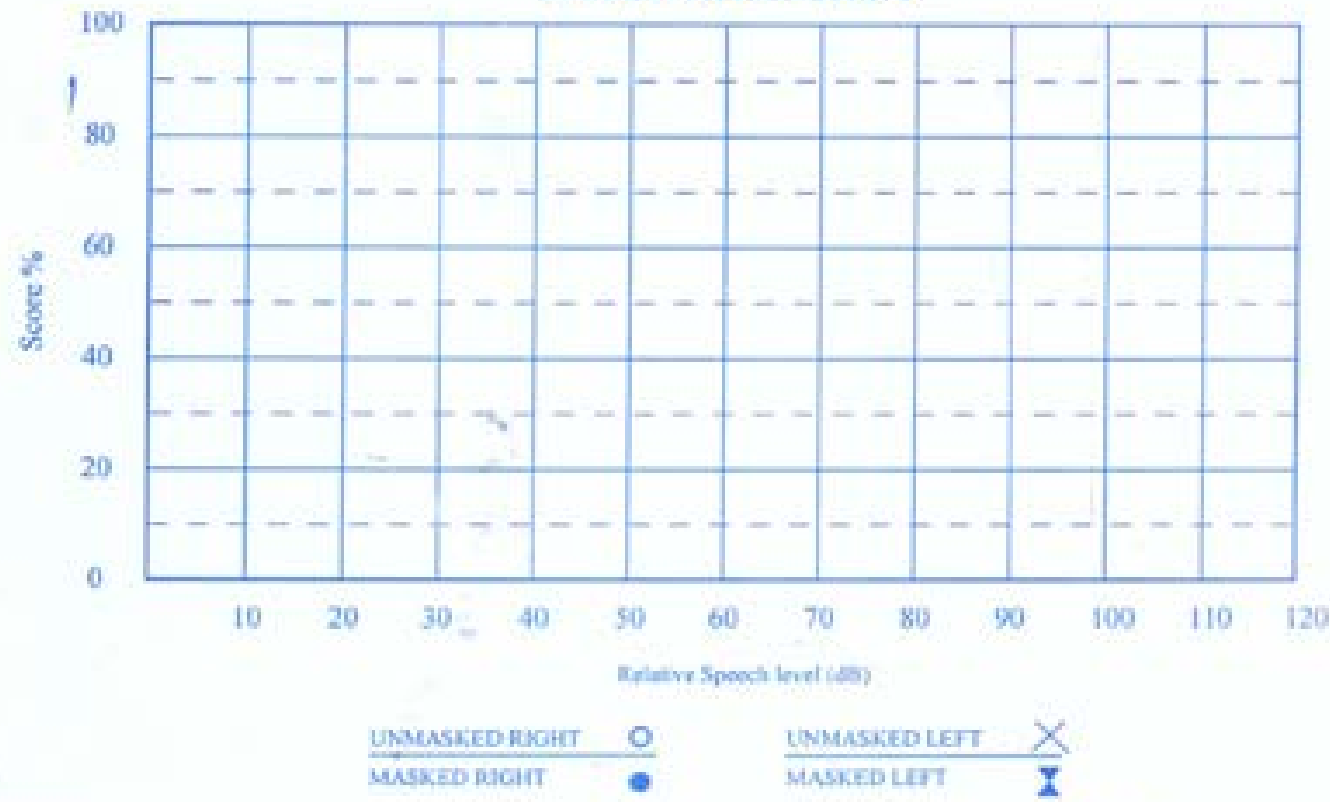

Spech material

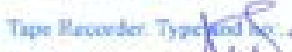

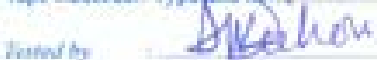




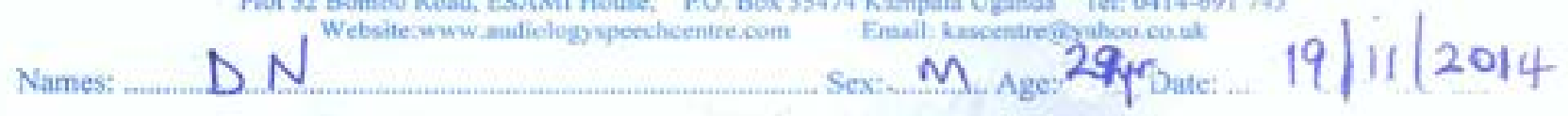

Address:

Tel:

Referal/ Advertisement:

P.T.AUDIOGRAM
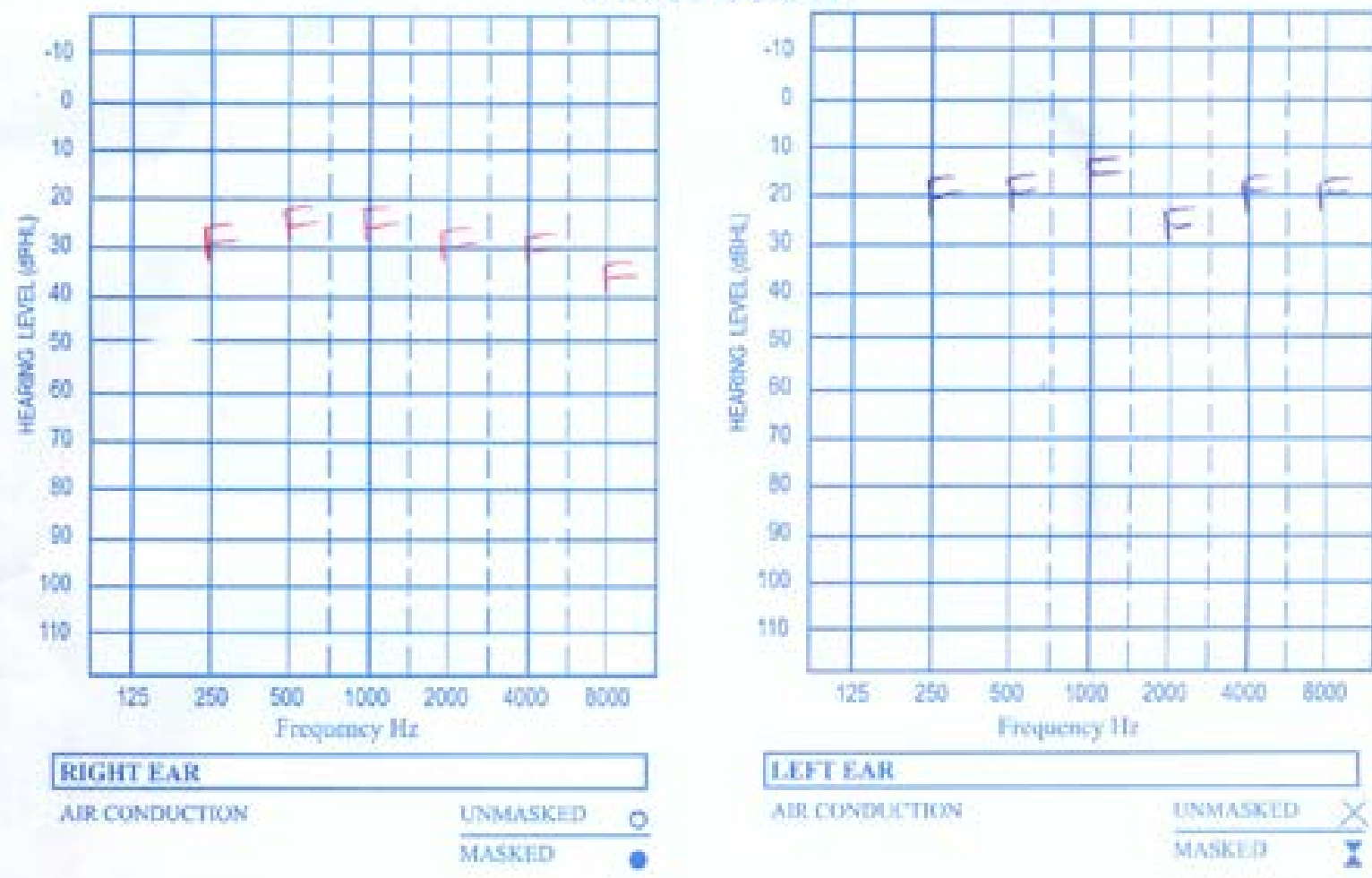

BONE CONDUCTION

$$
\frac{\text { UNMUSKED }}{\text { MASKED 【 }}
$$

BONE CONDUCTION

$\frac{\text { UNMASKFE } \triangle}{\text { MASKED }}$

Audiomater type and number. Dlagnostic AD 20 f

SPEECH AUDIOGRAM

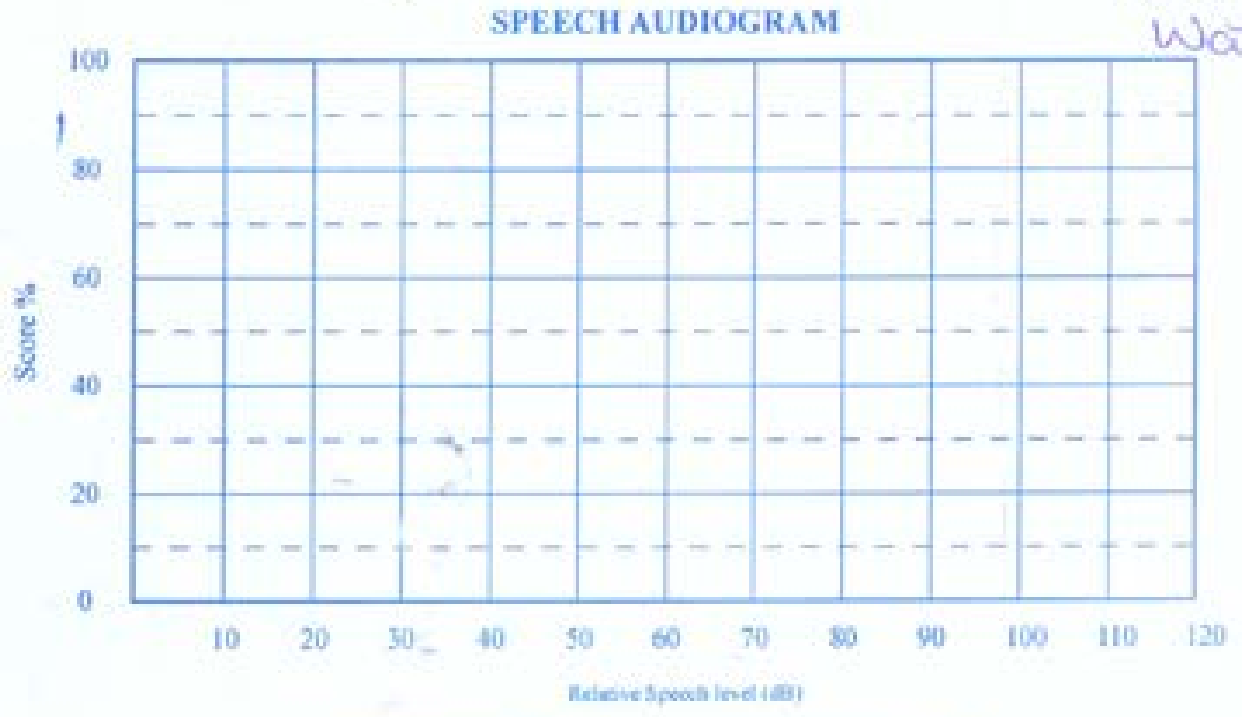

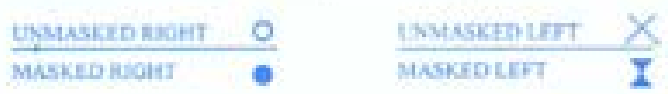

Soenct inateril

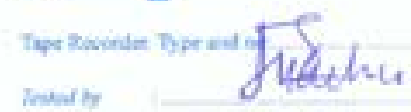


An MRI of the patient's temporal bone was not done, partly because the patient's cochlear apparatus was found to be normal on CT scan and also because of the high cost of carrying out an MRI scan.

He then had surgery on his right ear. Of the two ears, the right ear inspite of having cholesteatoma was considered to be safer than the left ear which had previously been diagnosed with tuberculosis .

The following procedures were done subtotal petrousectomy, blind sac of the external auditory canal, obstruction of the eustacian tube and fat graft to the cavity. Then we did the well for the CI receiver stimulator behind the mastoid, made a trough to the mastoid and opened the cochlear just inferior and anterior to the round window. The electrode was then inserted with an advance off stylet technique for a full insertion. The device was activated intra-operatively and impedances were obtained and neural response telemetry obtained. This confirmed the device integrity and the nerve responses to stimulation. We obtained a plain Stenver's view xray confirming electrode position with in the cochlear without kinks or bends.

The wounds were closed in the normal fashion and a firm mastoid dressing was placed. On the first postoperative day, we obtained threshold and comfort levels on each electrode and activated the processor. Then we obtained open set speech understanding to words and sentences.

The cochlear implant (CI) was activated on the first postoperative day remotely via internet with the help of the cochlear implant team at New York University Cochlear Implant Center and the patient was immediately able to appreciate some sounds. This was done using an application that had been put on one of Prof. Roland's laptop computer. The application is called Custom Sound by Cochlear (the company that manufactures the cochlear implant that was used). The patient also received a pneumococcal vaccine on the first postoperative day and was discharged from hospital the following day.

Follow up appointments were arranged for him with the local ENT team in Uganda, a speech therapist, and the Cochlear Implant center in New York University. After a usual postoperative course, he joined his mother in working in their family business.

\section{Discussion}

Hearing loss is not an uncommon problem in Uganda. Westerberg et $\mathrm{al}^{3}$ carried out a study in Uganda and found that the prevalence of disabling hearing impairment was $11.7 \%$ in adults and $10.2 \%$ in children. There are many causes of profound sensorineural hearing loss, however the cause of hearing loss in this young man is unknown. The incidence of tuberculosis otitis media has been reported to be $0.04 \%$ to $0.9 \%$ of all Chronic Suppurative Otitis Media (CSOM) in the developed countries $^{4,5}$ Although he suffered from TB(tuberculosis) of the ear and was treated with antiTB drugs for 8 months, there is still no clear evidence to incriminate the disease process or its treatment as the cause of the profound sensorineural hearing loss in both ears.

Normally, active chronic suppurative otitis media is regarded as a contraindication for cochlear implantation. In case of a radical cavity after surgical treatment for cholesteatoma, the electrode covered by the epithelial lining of the mastoid will likely become exposed or extruded. Under these circumstances some studies ${ }^{6,7}$, have shown that the some of the following procedures can be done to protect the electrode. These include subtotal petrosectomy, obliteration of the middle ear cleft with abdominal fat, mastoid obliteration and the blindsac closure of the external ear canal before cochlear implantation.

In this particular case, the operation was carried out in an infected ear. At the time of the operation, the right ear had a tympanic membrane perforation and scanty aural discharge and patient had been using ear drops to control the infection. And to safe guard against future complications in the same ear, the eustachian tube was completely blocked and the ear canal 'blind-sacked'. This we hope will protect the implant device from middle and outer ear infections.

Wei et $\mathrm{al}^{8}$ carried out a study that showed that vaccinating cochlear implant patients against $S$ pneumonia was protective against pneumococcal meningitis. Other studies have also showed that children with cochlear implants are at a higher risk for meningitis than children with hearing loss who have not received cochlear implants $^{9-11}$. In 2003, the CDC and FDA announced that children with cochlear implants are at a slightly increased risk of bacterial meningitis ${ }^{12}$. Though this risk is small, it is still 30 times higher than children in the general population, without proper immunizations. A study of 4,265 American children who received implants between 1997 and 2002 concluded that recipient children 
had a risk of pneumococcal meningitis more than 30 times greater than that for children in the general population. A later, UK-based, study found that while the incidence of meningitis in implanted adults was significantly higher than the general population, the incidence in children was not different than in the general population $^{13}$. Therefore to further protect our patient from any anticipated future complications like pneumococcal meningitis, he was given the pneumococcal vaccine on the first postoperative day.

Other than the ear infection, this young man was a good cochlear implant candidate because he had just recently lost his hearing (short duration of deafness) and his speech was well developed (post-lingual) by then. This means that rehabilitating him after the cochlear implant had been activated would require less intensive therapy. Still, the device is not an immediate fix and the patient still needed regular rehabilitation sessions to maximize performance. The candidate was also very motivated as far as wanting to receive the cochlear implant and being able to hear again was concerned and he had strong support from his parents and from the three speech therapists in Uganda. These factors are also very important in his success.

As of December 2010, approximately 219,000 people worldwide have received cochlear implants; in the U.S., roughly 42,600 adults and 28,400children are recipients. The vast majority are in developed countries due to the high cost of the device, surgery and post-implantation therapy $^{14,15}$, This cochlear implant operation was the first one done in Uganda and possibly the first in the East African region(no published report of any done before in this region). This compared to the numbers of cochlear implant operations done in the developed countries is too small a number but this is a very good starting point for us in Uganda. We have since then carried out another cochlear implant surgery on an adult male which was also successful.

Over the last 10 years, implant centers have begun to use the internet to allow audiologists to monitor devices from remote locations. In a study by Shapiro and colleagues $^{16}, 8$ patients were evaluated; 4 were monitored in situ and 4 from a remote location (cochlear implant center)in an effort to determine the feasibility and efficacy of remote monitoring compared with in situ monitoring. The results showed the average audiologist's time for remote testing was 9 minutes compared with 93 minutes required for performing in situ testing. In fact according to the cochlear implant team from New York University, this was the very first time they programmed/ activated a cochlear implant device on a patient from such a long distance using telemedicine (New York to Uganda, Africa).

The young man is doing well and is able to hear well six years after his operation. His hearing was assessed using an audiometer and his hearing was found to be very good ( see attached hearing test results).

As expected his hearing is much better in a quiet environment compared to more difficult listening conditions. This agreed with earlier studies which showed that for a patient with severe to profound sensorineural hearing impairment in both ears, their hearing can be restored to a good extent by implanting them with a cochlear implant ${ }^{17}$.

This cochlear implant operation is a very important landmark for Uganda in the field of otology, and we are grateful to our colleagues from New York University, USA and our Canadian friends from the Uganda Hearing Project for their collaborative effort and all the support they have given to us. This however is like the proverbial drop in the ocean concerning the need for otologic care for the many Ugandan patients with ear disease, but represents an important first step toward meeting this important need.

\section{Acknowledgements}

The authors would like to thank the Cochlear Implant Team at New York University, Mulago National Referral Hospital Staff (in particular the staff of the ENT and Speech Therapy Department for their administrative support in the organization and completion of this project. We also appreciate and thank Cochlear, (an American company that manufactures hearing devices), who freely donated the cochlear implant (an otherwise very expensive gadget).

\section{Consent}

Consent was obtained from the patient for publication of this case.

\section{Conflict of interest}

No conflict of interest to declare.

\section{Authors' contributions}

Prof. Thomas Roland, Drs Richard Byaruhanga, Mi- 
chael Awubwa and Chris Ndorelile participated in the surgery with Prof. Roland as the Chief Surgeon.

Drs. Richard Byaruhanga, Gustav Buname, Emily Kakande, Justine Namwagala and Prof. Roland contributed to writing up the paper and preparing it for publication.

\section{References}

1.Bradham.T.S, Carlson.M.L, Coelho.D.H et al. Cochlear Implants: Adult and Paediatric. Otolaryngologic Clinics of North America. Feb 2012.Vol 45, 1.

2. Zeng.F . Cochlear Implants in Developing Countries. Cochlear International Club International. 1996. Vol 10, (4) 5-9.

3. Westerberg BD, Lee PK, Lukwago L, Zaramba S, Bubikere S, Stewart I. Cross-sectional survey of hearing impairment and ear disease in Uganda. J Otolaryngol Head Neck Surg. 2008 Dec;37(6):753-8.

4. Siqueira-Batista R, Palheta-Neto FX, Gomes AP, Pezzin-Palheta AC (2002). Tuberculosis-related middle ear otitis: a rare occurance. Rev Soc Bras Med Trop 35:267-268.

5. Buname G, Namwagala J, Ndoleriire C, Alele D (2013) Tuberculous Mastoiditis: A rare occurrence. J Ifect Dis Ther 1:113. doi:104172/jidt.1000113

6. Issing PR, Schönermark MP, Winkelmann S, Kempf HG, Ernst A.Cochlear implantation in patients with chronic otitis: indications for subtotal petrosectomy and obliteration of the middle ear. Skull Base Surg. 1998;8(3):127-31.

7. Leung R, Briggs RJ Indications for and outcomes of mastoid obliteration in cochlear implantation. Otol Neurotol. 2007 Apr;28(3):330-4.

8. Wei BP, Robins-Browne RM, Shepherd RK, Azzopardi K, Clark GM, O'Leary SJ. Assessment of the protective effect of pneumococcal vaccination in preventing meningitis after cochlear implantation. Arch Otolaryngol Head Neck. Surg. 2007 Oct;133(10):987-94.
9. Biernath KR, Reefhuis J, Whitney CG, et al. Bacterial meningitis among children with cochlear implants beyond 24 months after implantation. Pediatrics 2006; 117:284-9.

10. Parner ET, Reefhuis J, Schendel D, et al. Hearing loss diagnosis followed by meningitis in Danish children, 1995-2004. Otolaryngol Head Neck Surg 2007; 136: 428-33.

11. Cohen NL, Hirsch BE. Current status of bacterial meningitis after cochlear implantation. Otol Neurotol 2010;31:1325-8.

12. Reefhuis.J, Honein.M.A, Whitney.C.G, Chamany.S, et al. Risk of Bacterial Meningitis in Children with Cochlear Implants From the National Center on Birth Defects and Developmental Disabilities (J.R., M.A.H., K.R.B., M.V., P.C., O.D., C.B.), the Epidemiology Program Office (J.R., S.C., K.B., S.M., S.A.), the National Center for Infectious Diseases (C.G.W., S.C.), and the National Immunization Program (K.B.), Centers for Disease Control and Prevention, Atlanta; the Food and Drug Administration, Rockville, Md. (E.A.M., A.G.); the New York City Department of Health and Mental Hygiene, New York (S.M.); and the Texas Department of Health, Austin (S.A.).

13. http://jpubhealth.oxfordjournals.org/cgi/content/ short/fdh188v1

14. Berruecos, Pedro. (2000). Cochlear implants: An international perspective - Latin American countries and Spain. Audiology. Hamilton: Jul/Aug 2000. Vol. 39, 4:221-225

15. http://en.wikipedia.org/wiki/cochlear_implant. iHealthBeat, Reporting Technology's Impact on Health Care .A service of the California Healthcare Foundation.

16. Shapiro WH, Huang T, Shaw T, et al. Remote intraoperative monitoring during cochlear implant surgery is feasible and efficient. Otol Neurotol 2008;29(4):495-8. 17. NIH Consensus Conference. Cochlear implants in adults and children. JAMA 1995; 274:1955-61 PubMed 